\title{
ПРАВОВЫЕ КОНЦЕПТЫ К ПРОЕКТУ КОНЦЕПЦИИ ОБЩЕСТВЕННОЙ БЕЗОПАСНОСТИ В РОССИЙСКОЙ ФЕДЕРАЦИИ НА ПЕРИОД ДО 2030 ГОДА
}

\section{LEGAL CONCEPTS FOR DRAFT PUBLIC SAFETY CONCEPT IN THE RUSSIAN FEDERATION UP TO 2030}

\section{A. Voronov}

Summary. The author, being a member of the interdepartmental working group for the preparation of the draft of the new Concept of Public Security in the Russian Federation for the period until 2030, based on the analysis of a sufficient array of regulatory framework in the area under study, as well as the draft of the new Concept, offers innovative legal ideas containing a creative character and aimed at improving one of their fundamental documents in the field of security.

Keywords: legal concepts, draft Concept of Public Security, Ministry of Internal Affairs of Russia, strategic planning, risk-oriented approach, institutions of civil society.
$\Pi$ роект новой редакции Концепции общественной безопасности в Российской Федерации на период 2030 г. (проект Концепции) подготовлен в рамках полномочий Министерства внутренних дел Российской Федерации, определенных Федеральным законом «О полиции» от 7 февраля 2011 г. № 3-Ф3 [1], Положением о Министерстве внутренних дел Российской Федерации и Типовым положением о территориальном органе Министерства внутренних дел Российской Федерации по субъекту Российской Федерации, утвержденных Указом Президента РФ от 21 декабря 2016 г. N699 [2], а также с учетом требований Федерального закона от 28 июня 2014 г. № 172-Ф3 «О стратегическом планировании в Российской Федерации» [3].

В соответствии с названными нормативными правовыми актами Министерство внутренних дел Российской Федерации (МВД России) является федеральным органом исполнительной власти, осуществляющим функции по выработке и реализации государственной политики и нормативно-правовому регулированию в сфере внутренних дел, в сфере контроля за оборотом наркотических средств, психотропных веществ и их прекурсоров, в сфере миграции (далее - сфера внутренних дел), а также правоприменительные функции по федеральному го-
Воронов Алексей Михайлович

Д.ю.н., профессор, г.н.С., Институт государства и права РАН; г.н.С., Академия Управления МВД России; эксперт Российской Академии наук adminlaw@igpran.ru

Аннотация. Автор, являясь членом межведомственной рабочей группы по подготовке проекта новой Концепции общественной безопасности в Российской Федерации на период до 2030 года, на основе анализа достаточного массива нормативной базы в исследуемой сфере, а также проекта новой Концепции предлагает инновационные правовые идеи, содержащие в себе созидательный характер, направленные на совершенствование одного их основополагающих документов в сфере безопасности.

Ключевые слова: правовые концепты, проект Концепции общественной безопасности, МВД России, стратегическое планирование, риск-ориентированный подход, институты гражданского общества.

сударственному контролю (надзору) в сфере внутренних дел.

В качестве основных задач МВД России определены: выработка и реализация государственной политики в сфере внутренних дел; нормативно-правовое регулирование в сфере внутренних дел; обеспечение защиты жизни, здоровья, прав и свобод граждан Российской Федерации, иностранных граждан, лиц без гражданства, противодействие преступности, охрана общественного порядка и собственности, обеспечение общественной безопасности, предоставление государственных услуг в сфере внутренних дел.

МВД России в своей деятельности руководствуется Конституцией Российской Федерации, общепризнанными принципами и нормами международного права, международными договорами Российской Федерации, федеральными конституционными законами, федеральными законами, актами Президента Российской Федерации и Правительства Российской Федерации, а также настоящим Положением.

Руководство деятельностью МВД России осуществляет Президент Российской Федерации. 
В сфере нормотворческой деятельности МВД России осуществляет такие полномочия как:

- формирование основных направлений государственной политики в сфере внутренних дел на основе анализа и прогнозирования состояния преступности, положения дел в области охраны общественного порядка, обеспечения общественной безопасности, миграционных процесCOB;

- разработка и реализация мер государственной политики в сфере внутренних дел, участие в осуществлении государственной политики Российской Федерации в отношении соотечественников, проживающих за рубежом;

- разработка и представление Президенту Российской Федерации и в Правительство Российской Федерации проектов федеральных конституционных законов, федеральных законов, актов Президента Российской Федерации и Правительства Российской Федерации по вопросам, относящимся к сфере внутренних дел;

- подготовка других документов, по которым требуется решение Президента Российской Федерации или Правительства Российской Федерации, по вопросам, относящимся к сфере внутренних дел.

При таком подходе, разработка и представление проекта Концепции осуществлялись в рамках компетенции МВД России и в полном соответствии с названными нормативными правовыми актами Президента Российской Федерации.

Основу содержания проекта Концепции образуют не имеющие аналогов положения, разработанные с учетом практики правоохранительной деятельности при чрезвычайных условиях, связанных с распространением новой коронавирусной инфекции COVID-19. В частности, в проекте Концепции разработчиками предлагается новый организационно-правовой механизм обеспечения защиты прав и свобод человека и гражданина в условиях чрезвычайных и непредвиденных обстоятельств длительного действия. Этот механизм основан на риск-ориентированном подходе, имеет выраженный инновационный характер, предполагает опору на передовые информационные технологи анализа больших данных, последовательное внедрение искусственного интеллекта.

Положения Концепции соответствуют нормам Конституции Российской Федерации, федеральным конституционным законам, положениям Федерального закона от 28 декабря 2010 г. № 390-Ф3 «О безопасности» [4], иным федеральным законам, нормативным правовым актам Президента Российской Федерации и Правительства Российской Федерации.
Положения проекта Концепции корреспондируются с понятийным аппаратом и иными положениями Стратегии национальной безопасности Российской Федерации [5]. При этом отдельные положения Стратегии национальной безопасности Российской Федерации уточняются применительно к сфере обеспечения общественной безопасности в Российской Федерации на современном этапе развития Российской государственности [6].

В проекте Концепции учтены положения основополагающих документов в области государственного стратегического планирования, в частности - Стратегии противодействия экстремизму в Российской Федерации до 2025 года [7], Стратегии государственной антинаркотической политики Российской Федерации до 2020 года [8], Стратегии государственной национальной политики Российской Федерации на период до 2025 года [9], Доктрины информационной безопасности Российской Федерации [10], Стратегии экономической безопасности Российской Федерации на период до 2030 года [11], Основ государственной политики Российской Федерации в области защиты населения и территорий от чрезвычайных ситуаций на период до 2030 года [12], Основ государственной политики Российской Федерации в области пожарной безопасности на период до 2030 года [13], Основ государственной политики Российской Федерации в области промышленной безопасности на период до 2025 года и дальнейшую перспективу [14], Основ государственной политики в области обеспечения ядерной и радиационной безопасности Российской Федерации на период до 2025 года и дальнейшую перспективу [15], Основ государственной политики Российской Федерации в области обеспечения химической и биологической безопасности на период до 2025 года и дальнейшую перспективу [16], Концепции государственной миграционной политики Российской Федерации на 2019-2025 годы [17], Концепции долгосрочного социально-экономического развития Российской Федерации на период до 2020 года [18].

С учетом изложенного, представляется целесообразным рассмотреть вопрос о форме и названии будущего документа, в контексте требований Федерального закона № 172-Ф3 «О стратегическом планировании в Российской Федерации». Указанный федеральный закон прямо не выделяет среди документов стратегического планирования такой вид, как «концепция». Кроме того, есть расхождение в теоретико-практическом восприятии Концепции, как вида документа стратегического планирования. С учетом изложенного, название рассматриваемого документа возможно определить как: «Стратегия общественной безопасности в Российской Федерации до 2030 года», что, по нашему мнению, придаст ей черты эффективного инструмента, направленного на монито- 
ринг и реализацию угроз и вызовов безопасности нашего Отечества.

Являясь продолжением эволюционных изменений в системе современных документов стратегического планирования, проект Концепции учитывает основы действующей Концепции общественной безопасности в Российской Федерации [19] но обладает при этом выраженной самостоятельностью и новизной. В документе отражен новейший опыт правоохранительной деятельности в чрезвычайных условиях, связанных с распространением новой коронавирусной инфекции COVID-19, актуализированы современные вызовы и угрозы общественной безопасности в Российской Федерации, уточняются цели, задачи, принципы и основные направления взаимодействия органов государственной власти, органов местного самоуправления с институтами гражданского общества в обеспечении общественной безопасности, защиты прав и свобод человека и гражданина в Российской Федерации.

Положения проекта Концепции имеют выраженный комплексный характер и направлены на развитие системы обеспечения общественной безопасности, консолидацию и оптимизацию усилий и сил по ее обеспечению, совершенствование политических, организационных, социально-экономических, информационных, правовых и иных мер обеспечения общественной безопасности [20]. Вопросы стратегического планирования, совершенствования государственного управления в иных областях безопасности, предусмотренных законодательством Российской Федерации, учитываются в проекте Концепции, исходя из их влияния на сферу общественной безопасности.

Проект Концепции в целом сохранил структуру действующей Концепции общественной безопасности в Российской Федерации. При этом существенным образом модернизировал механизм ее реализации.

В отличие от существующего подхода нами было предложено осуществлять реализацию Концепции органами государственной власти и органами местного самоуправления во взаимодействии с институтами гражданского общества на федеральном, региональном и местном уровнях поэтапно на основе программно-целевого планирования. При этом к достоинствам Концепции относится то, что в ней прописан механизм и формы участия в обеспечении общественной безопасности объединений граждан правоохранительной направленности, предложенный автором. На наш взгляд разработка эффективных механизмов сотрудничества государственных и негосударственных структур в сфере обеспечения общественной безопасности, позволит наладить максимально прямой контроль за состояни- ем общественной среды, вплотную подвести субъектов обеспечения общественной безопасности к реализации сервиса предварительного исключения рисков в сфере общественной безопасности.

Новеллой проекта Концепции является введение риск-ориентированного подхода к организации деятельности субъектов (органов) обеспечения общественной безопасности, предложенного автором настоящих строк на заседании межведомственной рабочей группы Правительства Российской Федерации по подготовке проекта Концепции, предполагающего оценку рисков в сфере общественной безопасности при анализе влияющих на ее состояние факторов, а также принятии управленческих решений, включая подготовку законодательных и иных нормативных правовых актов в сфере общественной безопасности. Риск-ориентированный подход не противоречит полномочиям МВД России по формированию государственной политики в сфере внутренних дел и соответствует современным потребностям общества и государства к обеспечению общественной безопасности в условиях «новой реальности» социально-экономических отношений [21].

Определение структуры, порядка формирования и функционирования перспективной системы управления рисками, а также вопросы ее взаимодействия с системой ситуационных центров, создаваемых федеральными органами исполнительной власти и органами государственной власти субъектов Российской Федерации относится к полномочиям Правительства Российской Федерации в соответствии с пунктом «е» статьи 114 Конституции Российской Федерации, согласно которой Правительство Российской Федерации осуществляет меры по обеспечению законности, прав и свобод граждан, охране собственности и общественного порядка, борьбе с преступностью.

В отличие от существующего подхода в проекте Концепции помимо наблюдаемых угроз общественной безопасности предлагается учитывать и прогнозируемые вызовы, что значительно расширяет горизонт стратегического планирования в сфере обеспечения общественной безопасности [22]. Однако вопрос о включении в категорию новых вызовов таких явлений как: «противодействие незаконной миграции» и «противодействие коррупции», за счет их изъятия из компетенции субъектов (органов) обеспечения общественной безопасности, представляется дискуссионным и подлежащим дополнительной проработке, в том числе, с учетом международных обязательств Российской Федерации. Названные явления остаются реальными угрозами безопасности современной России, а противодействие им - основными направлениями деятельности органов обеспечения общественной безопасности. 
Заслуживает внимания сформулированный в проекте Концепции прогноз развития фронта угроз общественной безопасности на период до 2030 года (п. 11 проекта). По мнению разработчиков, основными источниками угроз в этой сфере станут эксплуатация (функционирование) объектов хранения опасных веществ, технологий и материалов, в том числе радиологических и медико-биологических, а также объектов критической инфраструктуры, находящихся в неудовлетворительном (опасном) техническом состоянии. Об актуальности данного положения, к сожалению, свидетельствуют события, произошедшие 29 мая 2020 года, когда результате техногенной аварии порядка 20 тысяч тонн дизельного топлива разлилось около ТЭЦ-3 Норильско-Таймырской энергетической компании.

Следует согласиться с подходом к содержательному наполнению проекта Концепции, в основе которого попытка решить ряд теоретико-методологических задач в рамках коррекции действующей Концепции, соблюдая при этом преемственность и непрерывность государственного управления в рассматриваемой сфере.

На основании вышеизложенного, представляется целесообразным сделать некоторые умозаключения.

По результатам изучения проекта Концепции можно констатировать, что подготовлен документ, не имеющий аналогов, с точки зрения новизны подходов к обеспечению общественной безопасности, не только в отечественной, но и в международной практике правоохранительной деятельности. С учетом этого обстоятельства, высказанных замечаний и предложений, проект «Концепции общественной безопасности на период до 2030 года» может быть рекомендован к передаче для утверждения в Совет Безопасности Российской Федерации, а также контроля исполнения в форме предоставления ежегодного доклада Президенту Российской Федерации.

\section{ЛИТЕРАТУРА}

1. Федеральный закон «0 полиции» от 7 февраля 2011 г. ㄱ-Ф3 // Собрание законодательства РФ. 2011 г. № 7 ст. 900.

2. Указ Президента РФ от 21 декабря 2016 г. N699 «0б утверждении Положения о Министерстве внутренних дел Российской Федерации и Типового положения о территориальном органе Министерства внутренних дел Российской Федерации по субъекту Российской Федерации» (в редакции Указа Президента РФ от 25 декабря 2019 г. N619) // Собрание законодательства РФ. 2016 г. № 52 (часть V) ст. 7614

3. Федеральный закон от 28 июня 2014 г. № 172-Ф3 «0 стратегическом планировании в Российской Федерации» // Собрание законодательства РФ. 2014 . № 26 (часть 1) ст. 3378.

4. Федеральный закон от 28 декабря 2010 г. № 390-Ф3 (ред. от 06.02.2020) «0 безопасности» // Собрание законодательства РФ. 2011. № 1. Ст. 2.

5. Указ Президента РФ от 31 декабря 2015 г. № 683 «0 Стратегии национальной безопасности Российской Федерации» // Собрание законодательства РФ. 2016. № 1. Ч. ІІ. Ст. 212.

6. Кобзарь-Фролова М.Н. К вопросу сущности и содержании понятия «безопасность» в сфере здравоохранения // Современная наука: актуальные проблемы теории и практики. Серия: Экономика и право. 2020. № 2. С. 95-100.

7. Стратегия противодействия экстремизму в Российской Федерации до 2025 года (утв. Президентом РФ 28 ноября 2014 г. № Пр-2753) (ред. от 29.05.2020)// Справочная правовая система «КонсультантПлюс».

8. Указ Президента РФ от 9 июня 2010 г. № 690 (ред. от 23.02.2018) «06 утверждении Стратегии государственной антинаркотической политики Российской Федерации до 2020 года» // Собрание законодательства РФ. 2010. № 24. Ст. 3015.

9. Указ Президента РФ от 19 декабря 2012 г. № 1666 (ред. от 06.12.2018) «0 Стратегии государственной национальной политики Российской Федерации на период до 2025 года» // Собрание законодательства РФ. 2012. № 52. Ст. 7477.

10. Указ Президента РФ от 5 декабря 2016 г. № 646 «06 утверждении Доктрины информационной безопасности Российской Федерации» // Собрание законодательства РФ. 2016. № 50. Ст. 7074.

11. Указ Президента РФ от 13 мая 2017 г. № 208 «0 Стратегии экономической безопасности Российской Федерации на период до 2030 года»// Собрание законодательства РФ. 2017. № 20. С. 2902.

12. Указ Президента РФ от 11 января 2018 г. № 12 «0б утверждении Основ государственной политики Российской Федерации в области защиты населения и территорий от чрезвычайных ситуаций на период до 2030 года»// Собрание законодательства РФ. 2018. № 3. Ст. 515.

13. Указ Президента РФ от 1 января 2018 г. № 2 «0б утверждении Основ государственной политики Российской Федерации в области пожарной безопасности на период до 2030 года»// Собрание законодательства РФ. 2018. № 2. Ст. 411.

14. Распоряжение Правительства РФ от 17 сентября 2018 г. № 1952-р «0б утверждении плана мероприятий по реализации Основ государственной политики Российской Федерации в области промышленной безопасности на период до 2025 года и дальнейшую перспективу»// Собрание законодательства РФ. 2018. № 40. Ст. 6146.

15. Указ Президента РФ от 13 октября 2018 г. № 585 «0б утверждении Основ государственной политики в области обеспечения ядерной и радиационной безопасности Российской Федерации на период до 2025 года и дальнейшую перспективу»// Собрание законодательства РФ. 2018. № 42. Ч. II. Ст. 6447. 
16. Распоряжение Правительства РФ от 28 августа 2019 г. № 1906-р «0б утверждении плана мероприятий по реализации Основ государственной политики Российской Федерации в области обеспечения химической и биологической безопасности на период до 2025 года и дальнейшую перспективу»// Собрание законодательства РФ. 2019. № 36. Ст. 5062.

17. Указ Президента РФ от 31 октября 2018 г. № 622 «0 Концепции государственной миграционной политики Российской Федерации на $2019-2025$ годы» // Собрание законодательства РФ. 2018. № 45. С. 6917.

18. Распоряжение Правительства РФ от 17 ноября 2008 г. № 1662-р (ред. от 28.09.2018) «0 Концепции долгосрочного социально-экономического развития Российской Федерации на период до 2020 года» (вместе с «Концепцией долгосрочного социально-экономического развития Российской Федерации на период до 2020 года») // Собрание законодательства РФ. 2008. № 47. Ст. 5489.

19. Концепция общественной безопасности в Российской Федерации (утв. Президентом РФ 14.11.2013 № Пр-2685)

20. Редкоус В. М. Вопросы контрольной и надзорной деятельности в документах стратегического планирования в области обеспечения экономической безопасности //В сборнике: Национальная безопасность России: актуальные аспекты Сборник статей Всероссийской научно-практической конференции. 2019. C. 104-111.

21. Воронов А.М., Татарян В. Г. Анализ теории и практики обеспечения национальной безопасности и интересов личности, общества и государства // Вестник Московского университета МВД России. 2017. № 5. С. 35-39.

22. Воронов А.М., Воронов А. А., Земскова Т. С. Государственный сервис исполнительной власти как институт административного права // Безопасность бизнеса.2020. № 2. С. 13-19.

23. Кобзарь-Фролова М.Н. К вопросу о сущности и содержании понятия «безопасность» в сфере здравоохранения // Современная наука: актуальные проблемы теории и практики. Серия «Экономика и право», -№ 2,-2020, -с. 95-101

(с) Воронов Алексей Михайлович ( adminlaw@igpran.ru ).

Журнал «Современная наука: актуальные проблемы теории и практики»

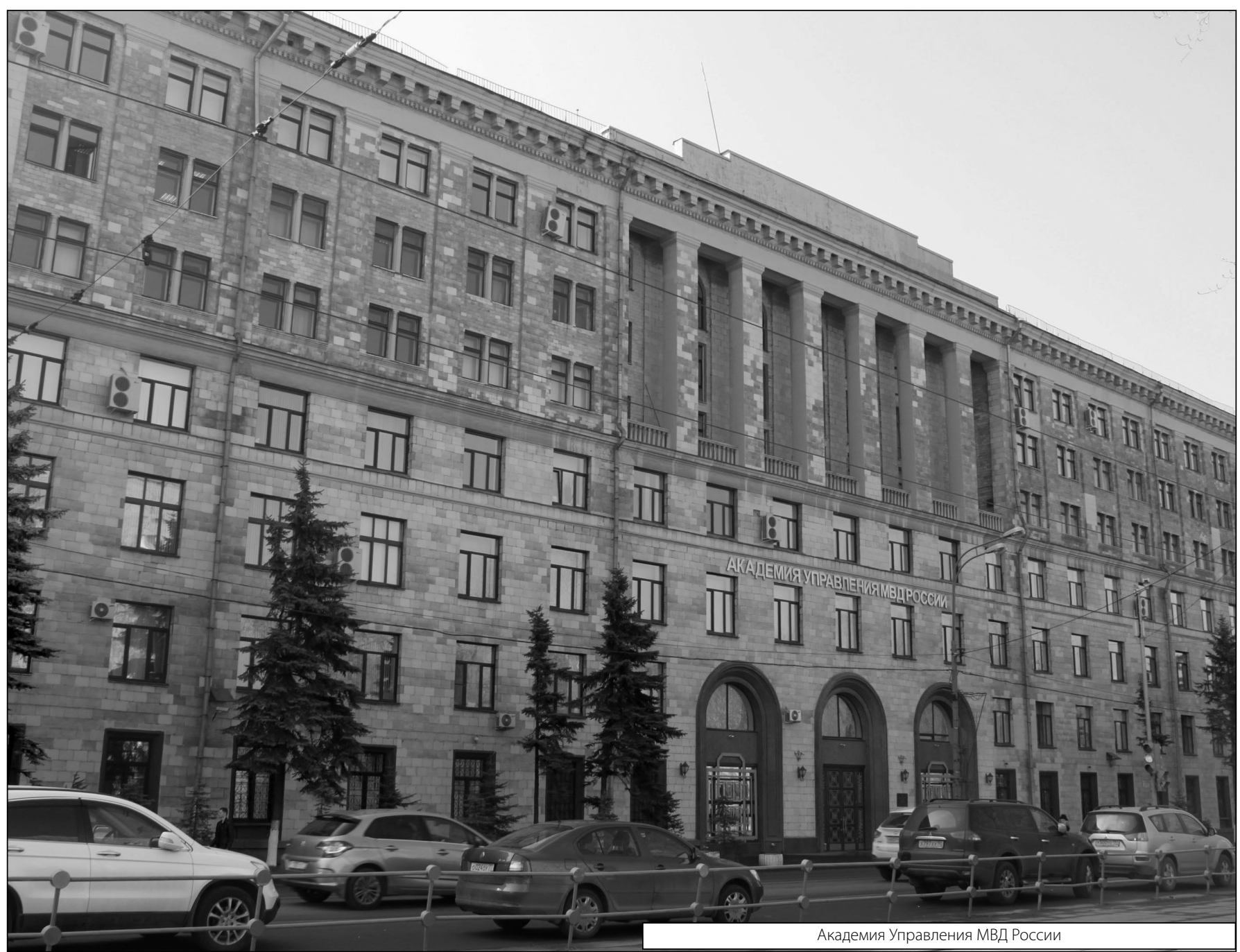

